\title{
Halina Sierocka
}

University of Białystok, Poland

e-mail: h.sierocka@uwb.edu.pl

ORCID: 0000-0002-6930-6409

\section{Violeta Jurković}

University of Ljubljana, Slovenia

e-mail: violeta.jurkovic@fpp.uni-lj.si

ORCID: 0000-0003-0730-5862

\section{Mirna Varga}

University of Osijek, Croatia

e-mail: mvarga@ffos.hr

\section{THE ROLE OF SMARTPHONES FOR ONLINE LANGUAGE USE IN THE CONTEXT OF POLISH AND CROATIAN STUDENTS OF DIFFERENT DISCIPLINES}

\begin{abstract}
Easy and cheap access to the Internet and a wide array of new technologies, such as smartphones, have multiplied opportunities for online informal learning of English (OILE). Yet, despite sizeable research, few studies have examined the issue of OILE in the context of university students of different disciplines. The aim of this research study was to examine the role of online language use through smartphones among students of various disciplines and its possible effects on enhancement of their foreign language skills. The study assumed both qualitative and quantitative methodology encompassing three research instruments: an online survey, the self-assessment language competence grid of the Common European Framework of Reference for Languages (CEFRL; Council of Europe, 2001) and a semi-structured interview. Data were collected with 377 students from two universities: University of Białystok, Poland and University of Osijek, Croatia. The research outcomes indicate that both Croatian and Polish students of different disciplines use their smartphones chiefly for receptive activities with infrequent use for language learning purposes and the predominant use of the mother tongue or English for the listed online activities through smartphones do not significantly affect the self-assessed level of their communicative competence in English. However, it can be stated that the choice of the preponderant language for online use through smartphones, especially for study-related issues, is conditioned by the students' discipline of study.

Keywords: English for Specific Purposes (ESP), communicative competence, mobile language learning, online informal learning of English (OILE), discipline of study.
\end{abstract}




\section{Introduction}

The modern world keeps offering new technologies and gadgets that promise better and faster ways of doing things. As the Statista Portal (2018) indicates, in 2016 an estimated $63 \%$ of the population worldwide owned a mobile phone and this mobile phone penetration is predicted to rise to $67 \%$ by 2019. In the USA, according to Flurry Analytics data (2018), 81\% of adult Americans now own a smartphone, which is intensively used both in their professional and private lives.

Language teachers are becoming aware that technological devices are present in every aspect of their students' daily lives hence they attempt to introduce technology into the process of instruction. There is abundant literature that investigates language learning with technology in and beyond the classroom, starting from the issue of CALL and blended learning (Jones, 1986; Banados, 2006; MacDonald, 2006; Sharma and Barrett, 2007; Hockly, 2011; Gruba and Hinkelman, 2012; Jarvis and Achilleos, 2013; Jarvis and Krashen, 2014; Tomlinson and Whittaker, 2013), through MobileAssisted Language Learning (MALL) (Kukulska-Hulme, 2009, KukulskaHulme, 2012; Burston, 2017) finishing with online informal learning of English (Socket, 2014; Socket and Kusyk, 2015; Kusyk, 2017; Lai et al. 2017; Trinder, 2017; Arndt and Woore, 2018; Jurkovič, 2019). Yet, not much research has been conducted to date that would refer to the use of technology among students of different disciplines.

\section{Purpose and context of the research}

Vocabulary is of key importance in any language learning as its knowledge helps to understand and use words and expressions appropriately in context, which is of particular significance as far as subject matter disciplines are concerned (Dudley-Evans and St. John, 1998: 80; Sierocka, 2014: 20). In that vein, two crucial questions might be posed, namely what vocabulary should be taught/learnt and how should this vocabulary be taught/learnt to gain the skills which enable people to communicate effectively in professional settings?

Some extensive research (Nation, 2006; Webb and Rodgers, 2009; Laufer and Ravenhorst-Kalovski, 2010) has been conducted to examine how many words learners need to know in order to read, listen to, or watch authentic English language input. The studies reveal that vocabulary demands are relatively high in terms of General English so we may assume that in the 
context of ESP the figures could be even higher. For example, to read authentic texts, as some scientists reveal (Nation, 2006; Laufer \& RavenhorstKalovski, 2010), learners should be familiar with the most frequent 8,000 word families to reach $98 \%$ lexical coverage, which means a rather lengthy process of language learning/teaching. As numerous scholars highlight, however, it may be compensated by the way vocabulary is acquired. Nation (2001: 388) states that "context with language in use should be given more time than decontextualized activities", therefore a language teacher should promote both direct and indirect vocabulary learning with the emphasis on the latter. Thus, out-of-class exposure to non-subtitled TV programs and movies, online resources and written print can contribute a lot to such indirect vocabulary learning, as it affords authentic language use (Pellicer-Sánchez and Schmitt, 2010; Lai et al, 2017), which in the context of scarcity of teaching materials for some disciplines cannot be underestimated.

Considering that modern technologies (the Internet, mobile phones etc.) constitute major venues and resources for indirect and autonomous language learning, the growing research (Kuppens, 2010; Lu, 2010; Stockwell, 2010; Toffoli and Sockett, 2010; Lee, 2017; Lyrigkou, 2017; Lai et al, 2017, Trinder, 2017; Jurkovič, 2019) on OILE (online informal learning of English) and its role in second language development is a natural consequence. OILE may be defined as a range of leisure activities, usually undertaken by non-native speakers without clear intention to improve the foreign language, involving exposure to and or use of English, from a variety of internet-based resources and interfaces like music, television series, blogs, vlogs etc. (Sockett and Kusyk, 2015: 1). The majority of research shows the invaluable role of OILE in incidental foreign language acquisition, particularly as far as vocabulary is concerned (Lu, 2008; Lee, 2017; Arndt and Woore, 2018; Peters, 2018; Peters and Webb, 2018). For example, the research conducted by Peters (2018) indicates that there is a positive relationship between learners' vocabulary knowledge and exposure to non-subtitled TV programs and movies, the Internet, and written print, and that out-of-class exposure might have a larger effect than length of instruction, which is promising in the context of acquisition of subject-related vocabulary.

The issue of online informal learning and mobile learning in a higher education context is gradually gaining more popularity among researchers and scholars (Traxler and Kukulska-Hulme, 2016; Herrando Rodrigo, 2017; Trinder, 2017; Crompton and Traxler, 2018); however, not much research has been conducted to date that would refer to online informal learning of languages and mobile language learning among students of different disci- 
plines. By this research project the authors hope to shed some light on the role of online informal learning of languages and mobile language learning among such students and the possible effects on enhancement of their foreign language skills. The research was conducted in the years 2017-2018 at the University of Bialystok in Poland and the University of Osijek in Croatia and among 377 students of various disciplines.

\section{Research methodology}

\subsection{Sample}

The quantitative part of the study was completed by 260 undergraduate students from the Faculty of Law of the University of Bialystok in Poland, and 117 undergraduate students from the University of Osijek in Croatia. The mean age and gender of the participants in both examined countries are presented in Table 1 (nine participants from Poland decided not to state their gender).

Table 1

Participants by age, gender, and nationality

\begin{tabular}{|l|c|c|c|c|}
\cline { 2 - 5 } \multicolumn{1}{c|}{} & \multicolumn{2}{c|}{ Age } & \multicolumn{2}{c|}{ Gender } \\
\cline { 2 - 5 } \multicolumn{1}{c|}{} & Mean & SD & Male & Female \\
\hline Poland & 20.96 & 1.76 & $35 \%$ & $62 \%$ \\
\hline Croatia & 19.97 & 1.81 & $18 \%$ & $82 \%$ \\
\hline
\end{tabular}

The independent samples t-test was used to compare the mean age of the participants from Poland and the mean age of the participants from Croatia. At the level of $p<0.05$ set for this study, the results show that the mean age of the participants from Poland is statistically significantly higher than that of their counterparts from Croatia $(t=2.835, p=0.000)$.

All participants from Poland with the exception of two come from the Faculty of Law. In Croatia, however, the distribution by discipline of study displays greater variety. $32 \%$ of the participants study information sciences, $52 \%$ psychology, and $16 \%$ linguistics.

Figure 1 shows the English language competence level of the participants according to the CEFRL self-assessment scale.

The data presented in Figure 1 show a highly similar distribution of values among the Polish and Croatian participants. The majority selfassessed their language competence to be at level B2 (49\% in Poland and 
The Role of Smartphones for Online Language Use in the Context of...

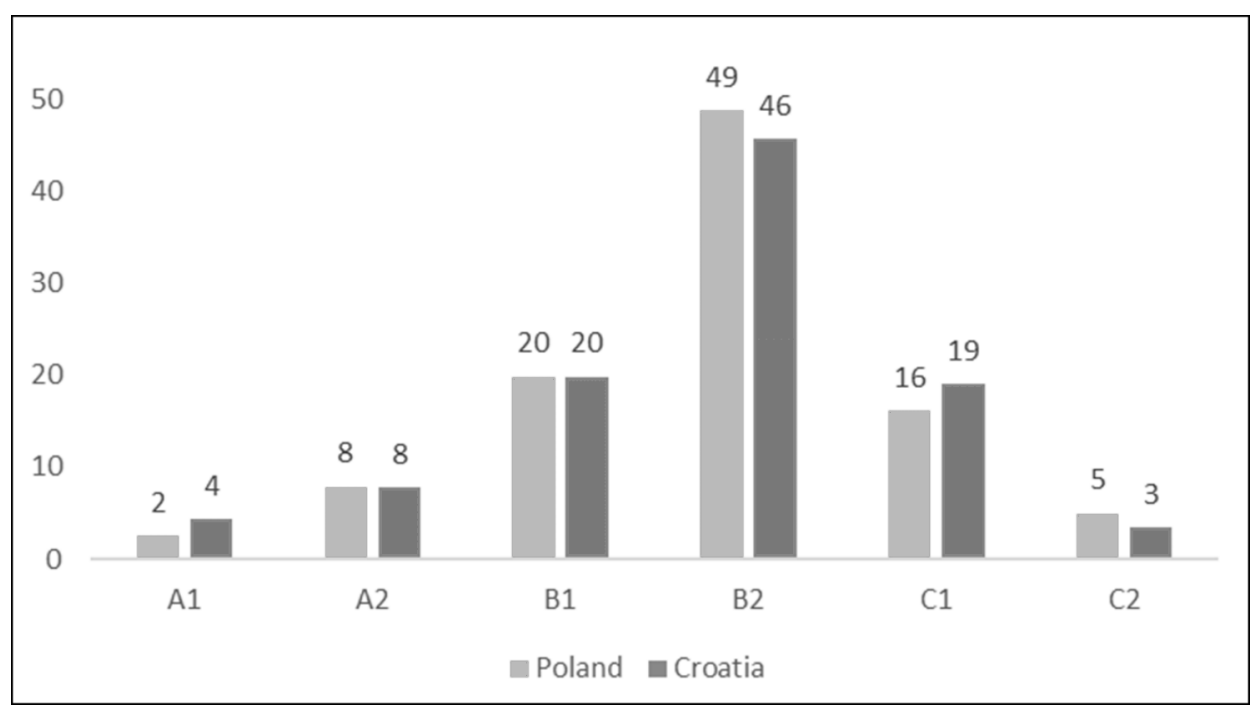

Figure 1. Participants by language competence in English

$46 \%$ in Croatia), followed by B1 (20\% in both countries), C1 (16\% in Poland and $19 \%$ in Croatia), A2 (8\% in both countries), C2 $5 \%$ in Poland and $3 \%$ in Croatia), and A1 (2\% in Poland and $4 \%$ in Croatia). The coefficients of skewness (-0.44) and kurtosis (0.50) indicate a normal distribution of this variable.

The independent samples t-test was conducted to test the differences in mean scores for self-assessed communicative competence in English among the Polish and Croatian participants. The results of the test and the descriptive statistics are shown in Table 2.

The results of the test show that the mean self-assessed communicative competence among the participants from Poland (3.83) is slightly higher but not statistically significantly different from the mean communicative competence among the Croatian participants (3.78).

Table 2

Communicative competence in English

\begin{tabular}{|l|c|c|c|c|}
\cline { 2 - 3 } \multicolumn{1}{c|}{} & Mean & SD & $t$ & Sig \\
\hline Poland & 3.83 & 1.04 & \multirow{2}{*}{-0.460} & 0.413 \\
\hline Croatia & 3.78 & 1.09 & & \\
\hline
\end{tabular}


Given that the age of the Polish participants was shown to be higher than that of the Croatian participants, Pearson's coefficient of correlation was used to test the association between two scale variables: age and selfassessed level of communicative competence. At $p=0.000$, the value of the coefficient (0.188) indicates a slight statistically significant positive correlation between age and self-assessed communicative competence in English. This means that a higher age value leads to a higher self-assessed communicative competence level, and vice versa.

In April 2018, the participants from the quantitative part of the study that left their contact addresses and expressed that they would be willing to participate in the qualitative part of the study were sent an invitation to participate in an interview. The final inventory of participants consisted of seven participants from Poland and seven from Croatia.

\subsection{Research questions}

As previously noted, with focus placed on smartphone use, the present study aims to address particular aspects of language use in online informal practices among students of different disciplines. To our knowledge, this is the first contrastive research in these two cultural settings, in which Poland is traditionally characterised by dubbing television and film programming whereas in Croatia video content is traditionally subtitled. The three research questions for this study are:

RQ1: What are the most frequent smartphone use activities among the Polish participants compared to those performed by their Croatian counterparts?

RQ2: What is the predominant language for online smartphones use among the Polish participants compared to their Croatian counterparts?

RQ3: What is the effect of the predominant language for online use on the self-assessed communicative competence level in English among the participants?

\subsection{Research instruments and data collection}

Three research instruments were used for the collection of data in this study: an online survey, the self-assessment language competence grid of the Common European Framework of Reference for Languages (CEFRL; Council of Europe, 2001), and semi-structured interviews.

The online survey used for the collection of quantitative data is the survey developed by Jurkovič (2019) for the analysis of smartphone uses and correlations with communicative competence levels among undergraduate 
students in Slovenia. The purpose of the survey was to collect quantitative data on the participants' age, gender, discipline of study, self-assessed level of communicative competence in English, use of smartphones for online activities, predominant online language when using smartphones, and predominant subtitling modes when watching films or television series in English through smartphones. The online survey was active from October to December 2017. Foreign language teachers at the Faculty of Law of the University of Bialystok in Poland and the University of Osijek in Croatia were asked to direct their participants to the online survey. Therefore, the selection of the participants was based on convenience sampling.

The English communicative competence level was assessed by the participants themselves through self-assessment using CEFRL descriptors (Council of Europe 2001, 26-27).

The qualitative part of the research was conducted after the completion of the quantitative analysis in April, 2018. The objective of the interviews was to further explore the findings of the quantitative analysis, in particular why for specific activities the mother tongue is chosen more often than English or vice versa, predominant subtitling modes when watching foreign films and TV series and how, in the opinion of the participants, using English online through their smartphones affects their English language development.

Triangulation engendered by a combination of quantitative and qualitative methods results in more detailed insight into the examined phenomenon (Stickler and Hampel, 2015). As a result, in addition to survey data that yielded quantitative results, the interviews were used for the collection of qualitative data. In this way the experience of the participants and their interpretations inform the findings that quantitative research alone cannot provide (Seidman, 2006).

\subsection{Research data analysis}

The online survey instructed participants to assess how often they used their smartphones to perform the listed online activities involving language use on a scale from 1 to 5 ( 1 - never or almost never, 2 - several times a month, 3 - several times a week, 4 - every day, 5 - several times a day). In the analysis two nominal variables were created to facilitate comparison with other studies (Kusyk, 2017; Trinder, 2017; Lyrigkou, 2018; Jurkovič, 2019): frequent users that use their smartphones for the listed activities at least several times a week (values 3 and higher), and infrequent users that use their smartphones for the listed activities several times a month or less often. 
The participants were also asked to indicate which language they most frequently used for a particular online activity. Value 1 indicated that they never used their smartphones for a particular activity, value 2 indicated their mother tongue, value 3 indicated English and value 4 indicated a foreign language other than English. Dichotomous variables were then created: the values of "I never do this" and using another foreign language were defined as missing values. Thus, value 1 was assigned to the mother language as the language most often used online through smartphones and value 2 was assigned to the English language as the language most often used online through smartphones.

IBM SPSS Statistics 23.0 was used for the analysis of quantitative data. Three statistical methods were used. The chi-square test was adopted for identifying significant relationships between two nominal variables (in this case, the frequency of smartphone activities and nationality, and predominant language for online use and nationality). Secondly, the independent samples t-test was used to compare two groups (in this paper the participants for whom their mother tongue or English is predominantly used online) through the mean value of the independent variable (in this case the self-assessed CEFRL level). Finally, Spearman's rho coefficient was used to test the association between watching films and television series in English (a nominal variable) and the self-assessed English communicative competence level (a scale variable).

Two-stage content analysis of interview transcripts was employed. First, the researchers read the data to familiarise with the relevant details that would provide further information of the investigated topic. Then, coding was applied to compare comments concerning similar categories. In the Results section, the interviewees were given the following codes: $\mathrm{P}=$ Polish participant, $\mathrm{C}=$ Croatian participant.

\section{Results}

\subsection{Smartphone use activities among the Polish participants compared to those among their Croatian peers}

The first research question addresses the most frequent smartphone uses among the Polish participants, and the differences between Polish and Croatian participants. Statistically significant associations, set at the level of $p<0.05$, are flagged with an *. The listed online activities are sorted in decreasing order by the share of frequent users among the Polish participants (Table 3). 
The Role of Smartphones for Online Language Use in the Context of...

\section{Table 3}

Shares of frequent users of online smartphone activities among the Polish and Croatian participants

\begin{tabular}{|c|c|c|c|c|}
\hline & \multicolumn{2}{|c|}{$\%$ of freq. users } & \multirow{2}{*}{$\begin{array}{l}\text { Chi- } \\
\text { square }\end{array}$} & \multirow{2}{*}{ Sig } \\
\hline & Poland & Croatia & & \\
\hline (P) I send short text messages. & 98 & 99 & 0.635 & 0.425 \\
\hline (R) I read social media comments. & 95 & 92 & 1.045 & 0.307 \\
\hline (R) I listen to music. & 94 & 97 & 1.751 & 0.186 \\
\hline (R) I watch short video clips with text. & 91 & 95 & 2.012 & 0.156 \\
\hline $\begin{array}{l}\text { I I communicate with my classmates on study- } \\
\text { related issues. }\end{array}$ & 90 & 96 & 3.083 & 0.214 \\
\hline (R) I read emails. & 83 & 87 & 0.984 & 0.321 \\
\hline (R) I look for study-related information. & 82 & 75 & 2.265 & 0.132 \\
\hline (R) I read the daily news. & 80 & 73 & 2.605 & 0.107 \\
\hline (R) I check non-study related information. & 76 & 76 & 0.009 & 0.924 \\
\hline (R) I read long texts. & 76 & 77 & 0.003 & 0.955 \\
\hline (P) I write emails. & 58 & 55 & 0.269 & 0.604 \\
\hline $\begin{array}{l}\text { (R) I watch foreign films and television series } \\
\text { in English with subtitles in my mother language. }\end{array}$ & 57 & 50 & 1.446 & 0.229 \\
\hline (LL) I access online dictionaries. & 54 & 38 & 7.608 & $0.006^{*}$ \\
\hline (P) I post social media comments. & 49 & 41 & 1.768 & 0.184 \\
\hline $\begin{array}{l}\text { (R) I watch films and television series in English with } \\
\text { subtitles in English or another foreign language. }\end{array}$ & 44 & 57 & 4.685 & $0.030^{*}$ \\
\hline (R) I listen to podcasts. & 39 & 35 & 0.503 & 0.478 \\
\hline $\begin{array}{l}\text { (LL) I use language learning apps that I have } \\
\text { downloaded onto my smartphone. }\end{array}$ & 35 & 14 & 16.149 & $0.000^{*}$ \\
\hline $\begin{array}{l}\text { (I) I communicate with my teachers on study- } \\
\text { related issues. }\end{array}$ & 34 & 44 & 2.986 & 0.084 \\
\hline $\begin{array}{l}\text { (R) I watch foreign films and television series } \\
\text { in English with no subtitles. }\end{array}$ & 34 & 46 & 4.872 & $0.027^{*}$ \\
\hline $\begin{array}{l}\text { (LL) I write down new words that I learn } \\
\text { in a foreign language. }\end{array}$ & 30 & 21 & 3.246 & 0.072 \\
\hline (R) I listen to radio shows. & 28 & 40 & 5.509 & 0.064 \\
\hline (P) I leave voice messages to other users. & 27 & 32 & 0.865 & 0.352 \\
\hline (R) I read e-books. & 25 & 19 & 1.608 & 0.205 \\
\hline (LL) I access websites with language learning exercises. & 24 & 11 & 8.571 & $0.003^{*}$ \\
\hline (R) I play games that require reading instructions. & 23 & 21 & 0.114 & 0.736 \\
\hline
\end{tabular}




\begin{tabular}{|c|c|c|c|c|c|}
\hline & \multicolumn{2}{|c|}{$\%$ of freq. users } & \multirow{2}{*}{$\begin{array}{l}\text { Chi- } \\
\text { square }\end{array}$} & \multirow{2}{*}{ Sig } \\
\hline & & Poland & Croatia & & \\
\hline & $\begin{array}{l}\text { I play games that require written communication } \\
\text { with other players. }\end{array}$ & 18 & 19 & 0.116 & 0.733 \\
\hline$(\mathrm{LL})$ & $\begin{array}{l}\text { I am a member of social media groups that talk } \\
\text { about language learning. }\end{array}$ & 17 & 12 & 1.632 & 0.201 \\
\hline & $\begin{array}{l}\text { I play games that require spoken communication } \\
\text { with other players. }\end{array}$ & 17 & 18 & 0.057 & 0.811 \\
\hline$(\mathrm{LL})$ & I play language games such as crosswords. & 17 & 13 & 0.668 & 0.414 \\
\hline$(\mathrm{R})$ & I listen to audio books. & 11 & 5 & 2.881 & 0.090 \\
\hline$(\mathrm{P})$ & I keep a blog. & 11 & 11 & 0.003 & 0.958 \\
\hline$(\mathrm{P})$ & I keep an audio blog. & 6 & 2 & 2.935 & 0.087 \\
\hline
\end{tabular}

The online activities involving language use performed by the participants using their smartphones can be divided into receptive activities (in Table 3 marked with an $\mathrm{R}$ ), productive activities (P), interaction activities (I), and language learning activities (LL). The latter are different from the previous three by their focus on the language form instead of meaning.

Of the online activities involving language use that are frequent among at least a half of the Polish participants, most can be classified as receptive activities. These are reading social media comments (frequent for $95 \%$ of the Polish participants), listening to music (94\%), watching short video clips (91\%), reading emails (83\%), looking for study-related information $(82 \%)$, reading the daily news $(80 \%)$, checking non-study related information $(76 \%)$, reading long texts $(76 \%)$, and watching foreign films or TV series with subtitles in Polish (57\%).

Among the thirteen online activities involving language use that are frequent for more than one half of the Polish participants, two productive activities can be found. These are sending short text messages $(98 \%)$ and writing emails (58\%). In addition, one interaction activity, communicating with classmates, is also frequent with $90 \%$ of frequent users. Among the language learning activities only one is frequent for more than one half of the Polish participants, which is accessing online dictionaries (54\%).

That smartphones are more frequently used for receptive activities than for productive activities is corroborated by two examples: the use of smartphones for reading and posting social media comments, and reading and writing email. In both cases the receptive activity is more frequent than the productive activity. If $95 \%$ of the Polish participants frequently use their smartphones to read social media comments, only $49 \%$ use 
them to post comments. Similarly, $83 \%$ of Polish participants read emails through their smartphones but only $58 \%$ frequently use smartphones to write emails.

Qualitative data reveal that the reasons for the predominant use of smartphones for receptive online activities are technological and psychological (Viberg and Grönlund, 2013), and temporal. The technological limitations of smartphones make them more suitable for receptive than for productive activities as is corroborated by, for instance, Polish participant P1: "In my opinion, the main reason for this fact is that smartphones are a little bit unpractical to post comments. The smartphone's monitor is too small, so it is uncomfortable to use it to post social media comments." Among the psychological reasons for infrequently using smartphones for productive activities the participants mentioned the wish to remain anonymous and the fear of losing face: "We write fewer comments much less because we are afraid that someone will 'hate' us, that is, we will be offended because we have expressed our individual opinions." (P6) Finally, reading as a receptive activity takes less time than writing as a productive activity, as has been mentioned by P4: "Not everyone wants to comment because writing takes time. For example, I sometimes comment if I have free time."

When watching foreign films and television series, more than one half of the Polish participants (57\%) watch them on their smartphones with subtitles in Polish, but less frequently with subtitles in English or in another foreign language (44\%), or with no subtitles (34\%). In this category two statistically significant differences between Polish and Croatian participants can be observed. Watching foreign films and television series with subtitles in their mother tongue is more common for Polish participants $(57 \%)$ whereas their Croatian counterparts, more frequently than using Croatian subtitles (50\%), use subtitles in English or another foreign language (57\%) or watch English films and television series with no subtitles (46\%). Watching foreign films and television series with no subtitles, on the other hand, is only frequent among $34 \%$ of Polish participants.

In terms of subtitling in English or in the mother language, the Polish and Croatian participants agree that English subtitles are easier to find: "When the video was recorded in another language, the English subtitles are most common and easy to find." (P5) or "It depends on the availability, my choice does not depend on the language." (C7). When considering how useful watching films and television series for the development of one's English, several Polish participants mentioned that having the words translated into Polish helps them learn new vocabulary: "Subtitles in Polish used in series 
or foreign films are needed to understand the film or series. Thanks to the subtitles, we hear a foreign accent and learn the words translated into Polish." (P6)

If the general distribution of receptive, productive, and interaction activities is compared between the two nationality groups, no significant differences can be observed: receptive activities prevail, only a few productive and interaction activities are performed. Using smartphones for language learning activities is infrequent among most participants in both groups. Nevertheless, some statistically significant differences between the two groups of participants by nationality can be observed. The smartphone activities involving language use that are more frequent among the Polish respondents are three language learning activities: accessing online dictionaries, using downloadable language learning apps, and accessing websites with language learning exercises.

The activities that are more frequently used among Croatian participants, on the other hand, are the receptive activities of watching films and television series with subtitles in English or another foreign language, and watching foreign films and television series in English with no subtitles. The qualitative data derived from interviews reveal that the Polish participants rely more often on subtitles in their mother language because in their opinion this enhances language learning, as mentioned earlier, and facilitates comprehension, especially if the English language use is not standard (P7): "When watching films or TV series in English subtitles in Polish and English can be used alternatively, Polish subtitles [appear] more often when the English used is slang or a hard-to-understand regional dialect."

\subsection{Predominant language for online use through smartphones among Polish participants compared to their Croatian counterparts}

The second research question addresses the predominant language that the Polish respondents use through smartphones compared to their Croatian counterparts. For the purpose of this analysis, the predominant language was examined for all online activities involving language use that are frequent for more than $50 \%$ of the participants in either group (see Table 4). These activities exclude watching films or television series in English because these two activities precondition the use of English instead of the mother language. Therefore, Table 4 presents the shares of participants that either selected their mother tongue or English as their predominant language of online use. The statistically significant differences between the two nationality groups are flagged with an $*$. 
The Role of Smartphones for Online Language Use in the Context of...

Table 4

Shares of participants by predominant language for online use through smartphones by nationality

\begin{tabular}{|c|c|c|c|c|c|c|}
\hline & \multicolumn{2}{|c|}{ Poland } & \multicolumn{2}{|c|}{ Croatia } & \multirow{2}{*}{$\begin{array}{l}\text { Chi- } \\
\text { square }\end{array}$} & \multirow{2}{*}{ Sig } \\
\hline & $\begin{array}{l}\text { Mother } \\
\text { tongue }\end{array}$ & English & $\begin{array}{l}\text { Mother } \\
\text { tongue }\end{array}$ & English & & \\
\hline (P) I send short text messages. & 91 & 9 & 88 & 12 & 0.551 & 0.458 \\
\hline (R) I read social media comments. & 64 & 36 & 42 & 58 & 13.214 & $0.000^{*}$ \\
\hline (R) I listen to music. & 22 & 78 & 7 & 93 & 10.446 & $0.001^{*}$ \\
\hline (R) I watch short video clips with text. & 39 & 61 & 96 & 4 & 42.743 & $0.000 *$ \\
\hline $\begin{array}{l}\text { (I) I communicate with my classmates } \\
\text { on study-related issues. }\end{array}$ & 97 & 3 & 99 & 1 & 1.048 & 0.306 \\
\hline (R) I read emails. & 93 & 7 & 90 & 10 & 0.537 & 0.464 \\
\hline (R) I look for study-related information. & 88 & 12 & 60 & 40 & 30.256 & $0.000^{*}$ \\
\hline (R) I read the daily news. & 79 & 21 & 77 & 23 & 0.076 & 0.783 \\
\hline $\begin{array}{l}\text { (R) I check non-study related } \\
\text { information. }\end{array}$ & 77 & 23 & 51 & 49 & 18.486 & $0.000^{*}$ \\
\hline (R) I read long texts. & 83 & 17 & 77 & 23 & 1.385 & 0.239 \\
\hline (P) I write emails. & 94 & 6 & 97 & 3 & 0.924 & 0.336 \\
\hline (LL) I access online dictionaries. & 47 & 53 & 14 & 86 & 24.374 & $0.000^{*}$ \\
\hline
\end{tabular}

Most Polish participants predominantly use their mother tongue for most of the listed activities: receptive (reading emails, looking for studyrelated information, reading the daily news, checking non-study related information, reading long texts), productive (sending short text messages, writing email), and interaction (communicating with their classmates on study-related issues). The only two exceptions where the English language is the predominant language of online use are activities related to popular culture content, i.e., listening to music and watching short video clips with text. To these we can add watching films and television series in English with or without subtitles because these activities inherently involve the use of the English language. In one activity both their mother tongue and English are extensively used, which is reading social media comments.

The chi-square test revealed several statistically significant differences between the two nationality groups. In general, it seems that in their online uses through smartphones the Polish respondents rely on their mother language much more than their Croatian counterparts. Thus, statistically 
significant differences can be observed in relation to reading social media comments, listening to music, watching short video clips with text, looking for study and non-study related information, and accessing online dictionaries; with the exception of the latter, all are receptive activities. On the other hand, the mother tongue is predominant among the participants from both nationality groups for all productive and interaction activities.

The main reason for using their mother tongue for interaction and productive activities is that communication usually takes place between two interlocutors sharing the same mother language: "In Poland we speak Polish It's our official language. That's the first reason. We were brought up in a Polish-speaking country and except communication with foreigners we speak Polish." (P3) and, similarly, "I always use Croatian when I am texting or messaging my friends because Croatian is our mother tongue. I do not feel the need to exchange messages in a foreign language. The same goes for email communication or posting social media comments because people I communicate with, i.e. my friends, acquaintances and professors, all speak Croatian so it is logical to post and write in Croatian." (C1)

The interviews indicated several reasons why the Polish respondents prefer their mother tongue to English for many among the listed activities. When looking for study-related materials, for example, ease of comprehension is the main criterion: "Because legal terminology is difficult even in Polish language." (P2) English, on the other hand, will be used when information is not found in Polish or when timely information is necessary: "Most information is written in English and only something can be found in the national languages, so I think that English should be used more often for study purposes." (P4) The discipline of study might have had an effect on this particular difference between the two groups. For students of psychology, for example, up-to-date sources are mostly available in English (C2): "When I need information for my studies I usually don't have an option since a lot of information that I need for my studies are written mostly in English which is a good thing because I also have the opportunity to expand my knowledge on English language."

An interesting finding is that for $22 \%$ of the Polish respondents most music that they listen to has lyrics in Polish. When asked about their preferred Polish music, they participants listed several different answers, from "Polish music from the 1970s and 1980s." (P1), "I like the music from the 1990s. Lyrics used in contemporary Polish music is terrible." (P3), or "I like to listen to rap music, for example Quebonafide, Taco Hemingway or Paluch." (P6). 
The Role of Smartphones for Online Language Use in the Context of...

\subsection{Effect of the predominant language for online use on the English communicative competence level}

In order to attempt to provide an answer to the third research question, the independent samples t-test was used to check the effect of the predominant language for online use on the self-assessed communicative competence level in English. As a result, the self-assessed communicative competence level in English was used as the test variable while the predominant language was used at the grouping variable. The results are presented in Table 5.

Table 5

Effect of the predominant language for online use on self-assessed communicative competence levels in English

\begin{tabular}{|c|c|c|}
\hline & $t$ & $p$ \\
\hline (P) I send short text messages. & -0.786 & 0.167 \\
\hline (R) I read social media comments. & -4.375 & 0.706 \\
\hline (R) I listen to music. & 0.934 & 0.412 \\
\hline (R) I watch short video clips with text. & -1.765 & 0.227 \\
\hline (I) I communicate with my classmates on study-related issues. & 0.522 & 0.324 \\
\hline (R) I read emails. & 0.267 & 0.126 \\
\hline (R) I look for study-related information. & -2.711 & 0.361 \\
\hline (R) I read the daily news. & -6.027 & 0.109 \\
\hline (R) I check non-study related information. & -4.595 & 0.693 \\
\hline (R) I read long texts. & -4.998 & 0.600 \\
\hline (P) I write emails. & -1.289 & 0.208 \\
\hline (LL) I access online dictionaries. & -2.732 & $0.019^{*}$ \\
\hline
\end{tabular}

The results indicate only one statistically significant effect, which indicates that the participants that self-assessed their communicative competence levels in English with lower ranks prefer using bilingual dictionaries involving their mother tongue instead of monolingual dictionaries. The other data show that the predominant use of the mother tongue or English for the listed online activities through smartphones does not have a statistically significant effect on the self-assessed level of the communicative competence in English. 


\section{Discussion}

The first research aspect examined related to most frequent smartphone use involving language use among Polish and Croatian students of different disciplines. The results show that both research groups use smartphone for the same purposes. The most popular activities involve sending short text messages (98\% of the Polish students and $99 \%$ of the Croatian peers respectively), reading social media comments (95\% of the Polish participants and $92 \%$ of the Croatian ones correspondingly), listening to music (94\% of the Polish students and $97 \%$ of the Croatian peers respectively), watching short video clips with text (91\% of the Polish participants and $95 \%$ of the Croatian ones correspondingly) or communicating with their classmates on study-related issues (90\% of the Polish students and $96 \%$ of the Croatian peers respectively). Moreover, after having analysed the data obtained for the first research question, it can be stated that no significant differences between the two nationality groups can be observed as far as general distribution of receptive, productive, and interaction activities are concerned. Both research groups use their smartphones predominantly for receptive activities with infrequent use for language learning purposes.

Interesting findings concern the question of predominant language for online use through smartphones. The research indicates that the mother tongues prevail in both nationality groups as far as all productive and interaction activities are concerned, which most probably results from the fact that the communication takes place between interlocutors of the same nationality thus the use of their native language is a natural thing. Nevertheless, both research groups differ significantly in relation to reading social media comments, listening to music, watching short video clips with text, looking for study and non-study related information and accessing online dictionaries. The study shows that Polish respondents rely more on their mother tongue than their Croatian peers (with the only exception which relates to popular culture content). The interviews conducted within this research project revealed that it is the discipline of their study i.e. subjectmatter specialism that might affect their preferences. In the case of the Polish respondents, who were mainly law students, ease of comprehension was the main factor which affected their choice of language use. Some commented that legal terminology is complicated in their native language thus reading study-related information in English could make it even more difficult or confusing. On the other hand, the Croatian students, who were students of information sciences, psychology, and linguistics, remarked that 
most up-to-date study-related resources are in English, so their choice was conditioned by the availability of scientific resources.

The third area approached relates to the effect of the predominant language for online use on the self-assessed level of communicative competence in English. The research outcomes show only one remarkable effect which concerns the fact that the respondents who assessed their communicative competence in English at a lower level prefer to use bilingual dictionaries to monolingual ones. The remaining data reveal that the predominant use of the mother tongue or English for the listed online activities through smartphones does not significantly affect the self-assessed level of communicative competence in English.

\section{Limitations of the study and suggestions for future research}

The authors of the paper are aware of a number of limitations of this research project which result from the specific research conditions (convenience of sampling was mainly used to select the research participants). The limitations refer to three areas. First, there is an obvious discrepancy in the sample number as the Croatian students (117 respondents) are outnumbered two to one by their Polish peers (260 respondents), which could affect the research results. Another limitation refers to age, which is significantly correlated with language competence. In the present study the age of the Croatian participants is considerably lower than that of Polish participants, which may lead to some assumptions that if the Croatian participants were at the same age as the Polish participants they could have higher language competence levels hence the findings could be interpreted in a different way. Nevertheless, this aspect requires some more research as the length of instruction does not always correspond to the achieved linguistic competence. Finally, the limitation refers to the variety of subject disciplines which are not reflected in both research groups. For the reasons stated above, the results of the present study although indicative and of practical didactic value are not representative and further research is recommended to determine whether the findings of this research might correspond to research outcomes that would refer to students of other nationalities and of other specialisations. 


\section{Conclusion}

Out-of-class learning with modern technology, with smartphones in particular, constitutes an essential context of second language development for specific purposes. Traditional printed materials, due to the specificity of subject matter disciplines in various university courses, may be insufficient and/or irrelevant and they are frequently supplemented by tailormade materials which are often easily available online. Therefore, online informal learning of English might play a special role in ESP instruction as it could give cheap and easy access to authentic materials, significantly increasing learners' motivation as students could learn what they want and how they want it.

In this study we have sought to address particular aspects of language use in online informal practices among university students of different disciplines in the Polish and Croatian context. The qualitative and quantitative methodology presented in this research project has revealed that Polish and Croatian students of different disciplines use smartphones (as far as language use is concerned) for the same purposes, mainly for receptive activities with infrequent use for language learning purposes i.e. sending short text messages, reading social media comments, listening to music, watching short video clips with text, or communicating with their classmates on study-related issues. Also, the respondents' mother tongue prevails in online use through smartphones, which is a natural thing if the interlocutors are of the same nationality. Finally, the study shows that predominant use of the mother tongue or English for the listed online activities through smartphones does not significantly affect the self-assessed level of communicative competence in English.

Despite some limitations, the results of this research project can serve as a reliable foundation for further studies in using modern technology to instruct students of different disciplines.

\section{R E F E R E N C E S}

Arndt, H. L. and R. Woore (2018) Vocabulary learning from watching YouTube videos and reading blog posts Language Learning and Technology 22 (3): $124-142$.

Banados, E. (2006) A blended-learning pedagogical model for teaching and learning EFL successfully through an online interactive multimedia environment. CALICO Journal 23/3: 533-550. 
The Role of Smartphones for Online Language Use in the Context of...

Burston, J. (2017) MALL: Global prospects and local implementation CALL-EJ, 18 (1): 1-8.

Council of Europe. (2001). Common European framework of reference for languages: Learning, teaching, assessment. Strasbourg: Language Policy Unit.

Crompton, H. and J. Traxler (2018) Mobile Learning and Higher Education. New York: Routledge.

Dudley-Evans, T. \& M. J. St John. (1998) Developments in English for Specific Purposes Cambridge: Cambridge University Press.

Gruba, P. and Hinkelman, J. (2012) Blended Technologies in Second Language Classrooms. Basingstoke: Palgrave Macmillan.

Herrando Rodrigo, I. (2017) Assisting language learning with new technologies: A case of Spanish degrees facing a European educational change process CALL-EJ, 18 (1): 40-61.

Hockly, N. (2011) Five things you always wanted to know about blended learning (but were afraid to ask). English Teaching Professional 75: 58.

Jarvis, H. and M. Achilleos (2013) From Computer Assisted Language Learning (CALL) to Mobile Assisted Language use. TESL-EJ 16 (4): 1-18. https://files.eric.ed.gov/fulltext/EJ1004355.pdf

Jarvis, H. and S.D. Krashen (2014) "Is CALL obsolete?" Language acquisition and language learning revisited in a digital age. TESL-EJ 17 (4): 1-6.

Jeong, K.-O. (2017) Preparing ELT student teachers with new technologies in the Korean context. CALL, 30: 488-509.

Jones, C. (1986) It's not so much the program, more what you do with it: the importance of methodology in CALL. System 14/2: 171-178.

Jurkovič, V. (2019). Online informal learning of English through smartphones in Slovenia. System, 80, 27-37. https://doi.org/10.1016/j.system.2018.10.007

Kukulska-Hulme, A. (2009) "Will mobile learning change language learning?" ReCALL 21 (2): 157-165. https://doi:org/10.1017/S0958344009000202

Kukulska-Hulme, A. (2012) 'Smart devices or people? A mobile learning quandary' International Journal of Learning and Media 4 (3-4): 73-77. https://doi.org/ 10.1162/IJLM_a_00105

Kuppens, A. H. (2010) Incidental foreign language acquisition from media exposure. Learning, Media and Technology, 35 (1): 65-85. https://doi.org/10.1080/174 39880903561876

Kusyk, M. (2017). The development of complexity, accuracy and fluency in L2 written production through informal participation in online activities. CALICO Journal, 34(1), 75-96.

Lai, C., Hu, X. and B. Lyu (2017) Understanding the nature of learners' out-of-class langauge learning experience with technology. CALL, 31 (1-2): 114-143. https://doi.org/10.1080/09588221.2017.1391293 
Laufer, B. and G. Ravenhorst-Kalovski (2010). Lexical threshold revisited: Lexical text coverage, learners' vocabulary size and comprehension. Reading in a Foreign Language, 22 (1): 15-30.

Lee, J.S. (2017) Informal digital learning of English and second language vocabulary outcomes: Can quantity conquer quality? British Journal of Educational Technology https://doi.org/10.1111/bjet.12599

Lu, M. (2008) Effectiveness of vocabulary learning via mobile phone. Journal of Computer Assisted Learning, 24: 515-525.

Lyrigkou, C. (2018) Not to be overlooked: Agency in informal language contact. Innovation in Language Learning and Teaching, 12, 1-16. https://doi.org/10.10 80/17501229.2018.1433182

MacDonald, J. (2006) Blended Learning and Online Tutoring. Aldershot, Hampshire: Gower.

Nation, P. (2001) Learning Vocabulary in Another Language. Cambridge: Cambridge University Press.

Nation, P. (2006) How large a vocabulary is needed for reading and listening? The Canadian Modern Language Review, 63 (1): 59-82. https://doi.org/10.1353/ cml.2006.0049

Pellicer-Sánchez, A., and N. Schmitt (2010) Incidental vocabulary acquisition from an authentic novel: Do Things Fall Apart? Reading in a Foreign Language, 22 (1): 31-55.

Peters, E. (2018) The effect of out-of-class exposure to English language media on learners' vocabulary knowledge.International Journal of Applied Linguistics 169: 1: 142-168. https://doi.org/10.1075/itl.00010.pet

Peters, E. and S. Webb (2018) Incidental vocabulary acquisition through viewing L2 television and factors that affect learning. Studies in Second Language Acquisition. Advance online publication. https://doi.org/10.1017/S0272263117 00040

Seidman, I. (2006) Interviewing as qualitative research. A guide for researchers in education and the social sciences. New York: Teachers College Press.

Sharma, P. and B. Barrett (2007) Blended Learning. Oxford: Macmillan.

Sierocka, H. (2014) Curriculum Development for Legal English Programs. Newcastle upon Tyne: Cambridge Scholars Publishing.

Stickler, U. and R. Hampel (2015). Qualitative research in CALL. CALICO Journal, 32(3), 380-395.

Socket, G. (2014) The Online Informal Learning of English. Basingstoke: Palgrave Macmillan.

Socket, G. and M. Kusyk (2015) Online informal learning of English: Frequency effects in the uptake of chunks of language from participation in web-based activities. In S.W. Eskildsen, \& T. Cadierno (eds.), Usage-based Perspectives on Second Language Learning (pp. 153-178). Berlin: DeGruyter. 
The Role of Smartphones for Online Language Use in the Context of...

Stockwell, G. (2010) Using mobile phones for vocabulary activities: examining the effect of the platform. Language Learning \& Technology, 14: 95-110.

Toffoli, D. and G. Sockett (2010) How non-specialist students of English practice informal learning using web 2.0 tools. Asp, la revue du GERAS 58: 125-144.

Tomlinson, B. and C. Whittaker (eds.) (2013) Blended Learning in English Language Teaching: Course Design and Implementation. London, England: British Council.

Traxler, J. and A. Kukulska-Hulme (2016) Mobile Learning. The Next Generation. New York: Routledge.

Trinder, R. (2017). Informal and deliberate learning with new technologies. ELT Journal, 71(4), 401-412.

Viberg, O. and A. Grönlund (2013). Cross-cultural analysis of users' attitudes toward the use of devices in second and foreign language learning in higher education: A case from Sweden and China. Computers \& Education, 69, 169-180. http://dx.doi.org/10.1016/j.compedu.2013.07.014

Webb, S. and M. P. H. Rodgers (2009) Vocabulary demands of television programs. Language Learning 59 (2): 335-366

http://onlinelibrary.wiley.com/doi/10.1111/j.1467-9922.2009.00509.x/full 